5 Smith R. "He never got over losing his job": death on the dole. $\mathrm{Br}$ Med $\mathrm{f}$ 1985;291:1492-5.

6 Smith R. "I'm just not right": the physical health of the unemployed. Br Med $\mathcal{F}$ 1985;291:1626-9.

7 Sabroe S, Iversen L. Unemployment, social support, psychological well-being and psychosomatic symptoms. In: Starrin B, Svensson PG, Winterberger $\mathrm{H}$, eds. Unemployment, poverty and quality of working life-some European experiences. Berlin: Edition Sigma (in press).

8 Kripke DF, Simons RN, Garfinkel L, Hammond EC. Short and long sleep and sleeping pills. Is increased morbidity associated? Arch Gen Psychiatry 1979;36:103-16.

9 Wingard DL, Berkman LF. Mortality risk associated with sleeping pattern among adults. Sleep 1983;6:102-7.

10 Berntorp K, Trell E, Thorell J, Hood B. Relation between plasma insulin and blood glucose in a cross-sectional population study of the oral glucose blood glucose in a cross-sectional population study of

11 Lindberg W, Natvig H, Rygh A, Svendsen H, Høyde- och viktundersøkelser hos voksne menn och kvinner. Tidsskr Nor Laegeforen 1956;11:361-8.

12 Goldberg D. Manual of the personal health questionnaire. Windsor: National Foundation for Educational Research, 1978.

13 Åkerstedt T, Gillberg M. Experimentally displaced sleep. Effect on sleepiness. Electroencephalogr Clin Neurophysiol 1982;54:220-6.

14 Åkerstedt T, Torsvall L, Gillberg M. Sleepiness and shift work: field studies. Sleep 1982;5:95-106.

15 Theorell T, Ahlberg-Hulthén G, Berggren T, et al. Arbetsmiljö, levnadsvanor och risk för hïärt-kärlsjukdom. Stockholm: National Institute for Psychosocial Factors and Health, Karolinska Institute, 1987. (Stress research report No 195.)

16 Theorell T, Harms-Ringdahl K, Ahlberg-Hulthén G, Westin B. Psychosocial job factors and symptoms from the spine and joints-a multicausal analysis. Scand F Rehabil Med (in press).
17 Lindgärde F. Potentiometric determination of serum ionized calcium in a normal human population. Clin Chim Acta 1972;40:477-84.

18 Dimsdale JE, Herd JA. Variability of plasma lipids in response to emotional arousal. Psychosom Med 1982;44:413-27.

19 Kasl S, Cobb S, Brooks G. Changes in serum uric acid and cholesterol levels in men undergoing job loss. FAMA 1968;206:1500-7.

20 Bryant HU, Story JA, "Yim GKW. Assessment of endogenous opioid mediation in stress-induced hypercholesterolemia in the rat. Psychosom Med 1988;50:576-85.

21 Arnetz BB, Brenner SO, Hjelm R, Levi L, Pettersson I. Stress reactions in relation to threat of job loss and actual unemployment. Stockholm: National Institute for Psychosocial Factors and Health, Karolinska Institute, 1988. (Stress research report No 206.)

22 Stamler J, Wentworth D, Neaton JD. Is relationship between serum cholesterol and risk of premature death from coronary heart disease continuous and grade

23 Ohira Y, Edgerton R, Gardner GW, Senewiratne B. Serum lipid levels in iron deficiency anemia and effects of various treatment. $\mathcal{F}$ Nutr Sci Vitaminol Tokyo) 1980;26:375-9.

24 Medeiros D, Pellum L, Brown B. Serum lipids and glucose as associated with haemoglobin levels and copper and zinc intake in young adults. Life Sci 1983;32:1897-1904.

25 Siegrist J. Sleep disturbances and cardiovascular risk: a biopsychosocial approach. In: Peter IH, Podstus T, Wichert PV, eds. Sleep related disorders and internal disease. Berlin: Springer, 1987:173-82.

26 Kristensson $\mathrm{H}$, Trell $\mathrm{E}$. Indicators of alcohol consumption. Comparisons between a questionnaire (Mn-MAST), interviews and serum-gammaglutamyltransferase (GGT) in a health survey of middle aged males. Brf Addict 1982;77:297-304.

(Accepted 19 fune 1990)
St Mary's Hospital,

Mumias, Kakamega

District, Kenya

M Keuter, MD, consultant

physician

Wilfreda A Ngwawe, nursing

officer in charge

Free University

of Amsterdam,

The Netherlands

Annemiek van Gijk, medical

student

Marjan Hoogstrate, medical

student

University of Amsterdam,

Amsterdam, The

Netherlands

Maarten Raasveld, medical

student

Marcel van der Ree, medical student

Wellcome Trust Research

Laboratories, Nairobi,

Kenya

William M Watkins, PHD,

interim director

Clinical Research Centre,

Kenya Medical Research

Institute, Nairobi, Kenya

Joab B O Were, MD, director

Division of Parasitic

Diseases, Center for

Infectious Diseases,

Centers for Disease

Control, Atlanta, Georgia,

United States

A David Brandling-Bennett,

MD, visiting scientist, Clinical

Research Centre

Correspondence to:

Dr Monique Keuter,

Department of Intensive

Care, Sint Radboud

Ziekenhuis, PO Box 9101,

6500 HB Nijmegen,

The Netherlands.

BrMed F 1990;301:466-70

\title{
Comparison of chloroquine, pyrimethamine and sulfadoxine, and chlorproguanil and dapsone as treatment for falciparum malaria in pregnant and non-pregnant women, Kakamega district, Kenya
}

Monique Keuter, Annemiek van Eijk, Marjan Hoogstrate, Maarten Raasveld, Marcel van de Ree, Wilfreda A Ngwawe, William M Watkins, Joab B O Were, A David Brandling-Bennett

\section{Abstract}

Objective-To compare treatment and protection against falciparum malaria in pregnant and nonpregnant women with three drug regimens.

Design-Prospective intervention study with six weeks' follow up. Patients received one of three drug regimens in order of entry.

Setting-Primary care hospital and secondary girls' school in rural western Kenya.

Patients -158 Of 988 pregnant women (89 primigravid and 69 multigravid) in the third trimester and 105 of 1488 non-pregnant schoolgirls of reproductive age were parasitaemic (more than 500 asexual forms $/ \mu$ l. These women were divided into three treatment groups by gravid state.

Interventions - Women were treated with chloroquine base $25 \mathrm{mg} / \mathrm{kg}$ over three days or pyrimethamine $75 \mathrm{mg}$ and sulfadoxine $1500 \mathrm{mg}$ as a single dose or chlorproguanil $1.2 \mathrm{mg} / \mathrm{kg}$ and dapsone $2.4 \mathrm{mg} / \mathrm{kg}$ as a single dose.

Main outcome measures-Parasitaemia and haemoglobin concentrations measured at seven day intervals for six weeks.

Results-Primigravid women were more likely to be parasitaemic on follow up than multigravidas or nulligravidas, whose response was about the same. Parasites did not clear by day 7 in primigravidas in six $(20 \%)$ of 30 who received chloroquine, three $(8 \%)$ of 35 treated with pyrimethamine and sulfadoxine, and none of $\mathbf{2 3}$ treated with chlorproguanil and dapsone. At day $28,83 \%, 19 \%$, and $67 \%$ of primigravidas in these treatment groups were parasitaemic. Haemoglobin concentrations rose in all women, but improvement was sustained only in women who remained free of parasites.

Conclusions-Clearance of parasites was better with either pyrimethamine and sulfadoxine or chlorproguanil and dapsone than with chloroquine.
Longest protection was obtained with pyrimethamine and sulfadoxine.

\section{Introduction}

Pregnant women, especially primigravidas, are more vulnerable than non-pregnant women to malaria infections. Infection may result in stillbirth, low birthweight infants, and anaemia in the mother. ${ }^{1-4}$ The World Health Organisation recommends that pregnant women receive chemoprophylaxis with chloroquine base, $5 \mathrm{mg} / \mathrm{kg}$ body weight weekly, in areas where Plasmodium falciparum is sensitive to the drug.'

In 1986 it was reported that chloroquine $5 \mathrm{mg} / \mathrm{kg}$ weekly and chloroquine $25 \mathrm{mg} / \mathrm{kg}$ monthly did not completely protect pregnant women in western Kenya. ${ }^{6}$ We found in 1987 that $90 \%$ of infections with $P$ falciparum in children under 5 years in western Kenya were resistant to chloroquine (unpublished data).

Two alternatives to chloroquine, amodiaquine and pyrimethamine with sulfadoxine, are no longer recommended for routine prophylaxis because of serious, though uncommon, side effects. ${ }^{7.9}$ The dihydrofolate reductase inhibitors pyrimethamine and chlorproguanil are not effective as prophylactic drugs in Kenya when given alone. ${ }^{10-12}$ Therefore only a limited number of drugs is available for effective prophylaxis.

A recent report indicates that the combination of chlorproguanil and dapsone is more effective than pyrimethamine and sulfadoxine in vitro and as effective in vivo against $P$ falciparum in Kenya. ${ }^{13}$ Because the chlorproguanil and dapsone combination is eliminated more rapidly than pyrimethamine and sulfadoxine, in one week compared with about eight weeks, chlorproguanil and dapsone may exert less pressure than pyrimethamine and sulfadoxine for the 
emergence of resistant parasites when the combination is given for treatment. Furthermore, the cost of a single dose of chlorproguanil and dapsone is the same as for a course of chloroquine, and the chlorproguanil and dapsone combination is considerably less expensive than pyrimethamine and sulfadoxine. Anticipating the need for new advice about treatment and chemoprophylaxis for pregnant women in areas with a moderate to high level of chloroquine resistance, we studied the response of $P$ falciparum infections in pregnant women to treatment with chloroquine, pyrimethamine and sulfadoxine, and chlorproguanil and dapsone. Our objectives were to determine which regimen would be most effective in eliminating parasites and for how long women would remain free of infection after treatment. We compared women of different gravid state in order to assess the effect of pregnancy on treatment outcome.

\section{Method}

From March through July 1988 all women 20 to 36 weeks pregnant who attended the antenatal clinic of St Mary's Hospital, Mumias, Kakamega District, Kenya, were screened for $P$ falciparum infection. This area of western Kenya is hyperendemic for malaria according to data from the Ministry of Health. Women who were positive for malaria parasites on blood film examination $(>500-<100000$ asexual forms $/ \mu \mathrm{l})$ and for whom a urine sample was negative for sulphonamides were assigned in order of entry (in blocks of three) to receive chloroquine base $25 \mathrm{mg} / \mathrm{kg}$ body weight given over three days; pyrimethamine $75 \mathrm{mg}$ and sulfadoxine $1500 \mathrm{mg}$ as a single dose; or chlorproguanil $1.2 \mathrm{mg} / \mathrm{kg}$ and dapsone $2.4 \mathrm{mg} / \mathrm{kg}$ body weight as a single dose. Initially, approval from the Kenya Medical Research Institute was obtained to study chloroquine and pyrimethamine with sulfadoxine in this group of pregnant women. After four weeks we were also allowed to investigate chlorproguanil with dapsone. As the results for the complete study did not differ from those after starting chlorproguanil with dapsone we present data from the entire study. All drugs were given orally and under supervision. Informed consent was obtained.

On day 0 a history was taken of symptoms (including fever, headache, joint pains, and vomiting) and antimalarial drug use in the preceding two weeks. Blood samples were taken for haemoglobin tests and for enzyme linked immunosorbent assays (ELISA) for

TABLE I-Characteristics of study population

\begin{tabular}{lcc}
\hline $\begin{array}{l}\text { No of } \\
\text { pregnancies }\end{array}$ & Mean age in years (range) & $\begin{array}{c}\text { Initial geometric } \\
\text { mean density of } \\
\text { parasites }\end{array}$ \\
\hline $0(n=105)$ & $15 \cdot 9(14-20)$ & 1461 \\
$1(n=89)$ & $18 \cdot 2(14-30)$ & 2085 \\
$>1(n=69)$ & $23 \cdot 3(15-39)$ & 1569
\end{tabular}

TABLE II-Response of malaria infected women after treatment with chloroquine, pyrimethamine and sulfadoxine, and chlorproguanil and dapsone

\begin{tabular}{|c|c|c|c|c|c|c|}
\hline \multirow[b]{2}{*}{ Treatment } & \multicolumn{6}{|c|}{ Cumulative No (\%) of women positive for parasites ${ }^{\star}$} \\
\hline & Day 7 & Day 14 & Day 21 & Day 28 & Day 35 & Day 42 \\
\hline \multicolumn{7}{|c|}{ Nulligravid women } \\
\hline Chloroquine $(n=31)$ & $4 / 31(13)$ & $5 / 31(16)$ & $12 / 31(39)$ & $13 / 31(42)$ & $16 / 31(52)$ & $18 / 31(58)$ \\
\hline Pyrimethamine and sulfadoxine $(n=36)$ & $2 / 36(6)$ & $2 / 36(6)$ & $2 / 36(6)$ & $2 / 36(6)$ & $5 / 35(14)$ & $5 / 34(15)$ \\
\hline Chlorproguanil and dapsone $(n=38)$ & $0 / 38(0)$ & $2 / 38(5)$ & $2 / 38(5)$ & $4 / 38(11)$ & $7 / 36(19)$ & $9 / 33(27)$ \\
\hline \multicolumn{7}{|c|}{ Multigravid women } \\
\hline Chloroquine $(n=28)$ & $3 / 28(11)$ & $4 / 27(15)$ & $6 / 23(26)$ & $12 / 23(52)$ & $16 / 22(73)$ & $17 / 21(81)$ \\
\hline Pyrimethamine and sulfadoxine $(\mathrm{n}=20)$ & $0 / 19(0)$ & $1 / 19(5)$ & $1 / 16(6)$ & $1 / 15(7)$ & $1 / 13(8)$ & $1 / 12(8)$ \\
\hline Chlorproguanil and dapsone $(n=21)$ & $0 / 21(0)$ & $0 / 19(0)$ & $0 / 18(0)$ & $3 / 17(18)$ & $5 / 15(33)$ & $7 / 11(64)$ \\
\hline \multicolumn{7}{|c|}{ Primigravid women } \\
\hline Chloroquine ( $\mathrm{n}=30$ ) & $6 / 30(20)$ & $11 / 30(37)$ & $20 / 29(69)$ & $22 / 29(76)$ & $24 / 29(83)$ & $25 / 29(86)$ \\
\hline Pyrimethamine and sulfadoxine $(n=36)$ & $3 / 35(9)$ & $4 / 33(12)$ & $6 / 31(19)$ & $6 / 31(19)$ & $7 / 28(25)$ & $8 / 27(30)$ \\
\hline Chlorproguanil and dapsone $(n=23)$ & $0 / 23(0)$ & $2 / 21(10)$ & $7 / 19(37)$ & $12 / 18(67)$ & $15 / 16(94)$ & $15 / 16(94)$ \\
\hline
\end{tabular}

4-aminoquinolines ${ }^{14}$; the latter were stored on filter paper. Urine was examined for sulfonamides with the Bratton-Marshall test. ${ }^{15}$ Blood films were stained with Giemsa stain; parasites were counted per 300 white blood cells and then adjusted to parasites per microlitre, assuming 8000 white blood cells per microlitre. Haemoglobin was measured with a colorimeter (Corning 252).

Women were asked to come back each week for six weeks after treatment. Money for transport was provided. If they did not show up we tried to trace them in the villages. (That this was not easy shows in the high dropout rate.) Each week a blood film was examined for parasites, the haemoglobin concentration was checked, and women were asked about their symptoms. Urine was collected from the women who received chlorproguanil with dapsone on days $1,7,14$, and 21 and stored for measurement of chlorproguanil, dapsone, and chloroquine by ELISA. ${ }^{14}$ During follow up the women who again became parasitaemic and had symptoms or signs of malaria and all those who had $>10000$ parasites $/ \mu$ l were treated with pyrimethamine and sulfadoxine. Adventitious problems such as urinary tract infections were treated with drugs without antimalarial or oxidant activity. No haematinic drugs or antihelmintic drugs were given during the study.

Nulligravid women who attended a secondary boarding school were screened and assigned to the same types of treatment groups as the pregnant women. That they were not pregnant was confirmed by a urine test for human chorionic gonadotropin. At day 14 after treatment urine was collected from those who had received pyrimethamine and sulfadoxine to measure pyrimethamine and sulfadoxine levels by ELISA.

Comparisons were done with Student's $t$ test, the $\chi^{2}$ test, and Fisher's exact test.

\section{Results}

\section{STUDY POPULATION}

Of 988 pregnant women who were screened, $182(18 \%)$ fulfilled the study criteria and 158 were included in the final analysis. Primigravidas were parasitaemic ( $>500$ parasites $/ \mu \mathrm{l})$ more often than multigravidas, $41 \%(101 / 249)$ and $11 \%(81 / 739)$ respectively. Of 1488 non-pregnant women, $105(7 \%)$ were enrolled as controls: the mean age of the nonpregnant women in the three treatment groups was the same, and there were no differences in age, period of gestation, or parity among the three treatment groups of pregnant women.

Table I shows the characteristics of the study population by number of pregnancies. Mean age increased with an increase in the number of pregnancies, as would be expected. The initial geometric mean density of parasite was significantly higher in the primigravid women than in the other groups $(p<0 \cdot 05)$.

\section{RESPONSE TO TREATMENT}

Table II shows response to the various treatment regimens. At day 7 chlorproguanil with dapsone and pyrimethamine with sulfadoxine were significantly better than chloroquine at clearing parasites in nulligravidas and primigravidas $(\mathrm{p}<0.05)$; at that point there was no difference between the regimens in multigravidas. The proportion of women who remained free of parasites at day 14 and day 21 was higher among those who received either chlorproguanil and dapsone or pyrimethamine and sulfadoxine, regardless of gravid state, than in those given chloroquine $(p<0.05)$. By day 21 the proportion of primigravid recipients of chlorproguanil and dapsone who were again infected had begun to increase, and it was similar to that in 
chloroquine recipients by day 35 . A slower but similar increase was seen in multigravid recipients of chlorproguanil and dapsone. Among all pregnant women significantly fewer recipients of pyrimethamine and sulfadoxine had become infected by day $42(p<0 \cdot 01)$.

The initial geometric mean parasite density in the primigravid women who became positive at day 14 after treatment with chlorproguanil and dapsone was significantly higher than that in women who were aparasitaemic on that day (7293 and 1633 respectively, $\mathrm{p}<0.05$ ). In the other groups of women the initial density of parasites was not related to subsequent reappearance of infection.

Less than $16 \%$ of subjects in all groups reported using chloroquine in the preceding two weeks. Use of chloroquine was not related to subsequent development of parasitaemia in any treatment group.

In urine samples collected from recipients of chlorproguanil and dapsone on day 1 chloroquine could be detected in only one sample, but chlorproguanil and dapsone could be detected in all samples. A few urine samples were positive for chlorproguanil and dapsone at day 7 . In urine samples collected from nulligravid recipients of pyrimethamine and sulfadoxine at day 14 pyrimethamine and sulfadoxine were present in all except one sample. The woman whose urine lacked these drugs was parasitaemic on day 14 .

\section{HAEMOGLOBIN CONCENTRATIONS}

Table III shows the increase in haemoglobin concentrations from day 0 to day 28 . On day 28 an increase in

TABLE III-Increase in mean haemoglobin concentrations in malaria infected women by number of pregnancies and treatment type

\begin{tabular}{|c|c|c|}
\hline $\begin{array}{l}\text { No of } \\
\text { pregnancies }\end{array}$ & $\begin{array}{l}\text { Haemoglobin concentration } \\
\text { at day } 0(\mathrm{mmol} / \mathrm{l})\end{array}$ & $\begin{array}{l}\text { Mean difference at } \\
\text { day } 28(\mathrm{mmol} / \mathrm{l}) \\
(95 \% \text { confidence } \\
\text { interval })\end{array}$ \\
\hline \multicolumn{3}{|c|}{ Treatment with chloroquine } \\
\hline $0(n=30)$ & $10 \cdot 1$ & $0.3(-0.11$ to 0.71$)$ \\
\hline $1(n=17)$ & $7 \cdot 9$ & $-0.2(-0.63$ to 1.03$)$ \\
\hline$>1(n=17)$ & $8 \cdot 0$ & $1.08(0.25$ to 1.91$)$ \\
\hline \multicolumn{3}{|c|}{ Treatment with pyrimethamine and sulfadoxine } \\
\hline $0(n=36)$ & $9 \cdot 5$ & $0.7(0.28$ to 1.12$)$ \\
\hline $1(n=26)$ & $7 \cdot 7$ & $0.44(-0.20$ to 1.08$)$ \\
\hline$>1(n=13)$ & $7 \cdot 7$ & $0.46(-0.13$ to 1.05$)$ \\
\hline \multicolumn{3}{|c|}{ Treatment with chlorproguanil and dapsone } \\
\hline $0(n=37)$ & $10 \cdot 2$ & $0.37(0.05$ to 0.69$)$ \\
\hline $1(n=9)$ & $7 \cdot 0$ & $0.70(-0.22$ to $1 \cdot 62)$ \\
\hline$>1(n=16)$ & $7 \cdot 5$ & $0.33(-0.27$ to 0.93$)$ \\
\hline
\end{tabular}

the haemoglobin concentration was seen in all groups except primigravid recipients of chloroquine. The rise was significant only in multigravidas treated with chloroquine and nulligravidas treated with pyrimethamine and sulfadoxine or chlorproguanil and dapsone. The increase in haemoglobin concentration continued until day 42 in nulligravid women. The rise in haemoglobin values, by treatment, was $0.85(95 \%$ confidence interval 0.50 to 1.20$) \mathrm{mmol} / \mathrm{l}$ for chloroquine, $1.44(0.97$ to 1.91$) \mathrm{mmol} / 1$ for pyrimethamine and sulfadoxine, and $0.61(0.16$ to 1.06$) \mathrm{mmol} / \mathrm{l}$ for chlorproguanil and dapsone. In the other groups the haemoglobin concentration decreased to its initial value.

We grouped the 158 pregnant women into those who remained free of parasites until day 28 , regardless of treatment, and those who became parasitaemic before or at day 28 . There was no difference in the initial geometric mean parasite density in these groups. During those four weeks $34(22 \%)$ women were lost to follow up and $56(35 \%)$ became parasitaemic. The mean haemoglobin concentration of the 68 women who remained aparasitaemic rose significantly from day 0 to day $28(0.59 \mathrm{mmol} / 1(0 \cdot 15$ to $1 \cdot 03))$. A significant increase was also seen in the women who became parasitaemic $(0.85 \mathrm{mmol} / \mathrm{l}(0.26$ to $1 \cdot 44))$, but this analysis did not include the 28 women who developed parasites and had symptoms before day 28 and were treated with pyrimethamine and sulfadoxine.

All pregnant women were compared for presence or absence of parasites on day 42 . The 41 women who remained free of parasites through day 42 maintained the significant increase in haemoglobin concentration $(0.52 \mathrm{mmol} / \mathrm{l}, 0.16$ to 0.88$)$ whereas the haemoglobin concentration fell toward initial values in those who became parasitaemic.

\section{Discussion}

Several authors have reported that primigravid women are more susceptible than nulligravid women to malaria, probably because of an altered immune response related to the presence of a new organ, the placenta, or to changes in splenic function induced by pregnancy. ${ }^{417}$ We found that primigravid women were more likely than nulligravid and multigravid women to be infected with $P$ falciparum, to remain parasitaemic at day 7 after treatment, and to have more instances of recrudescence or reinfection, regardless of treatment. Our results agree with earlier reports from western Kenya that multigravid women had the same response to chloroquine treatment (and, in our case, to treatment with pyrimethamine and sulfadoxine and chlorproguanil and dapsone) until day 28 as did nulligravid women. ${ }^{6}$ We found that $16 \%$ of multigravidas, $37 \%$ of primigravidas, and $15 \%$ of nulligravidas were parasitaemic by day 14 after treatment with chloroquine $25 \mathrm{mg} / \mathrm{kg}$ (table II).

Pyrimethamine with sulfadoxine and chlorproguanil with dapsone were equally effective for treatment of falciparum malaria and superior to chloroquine in all women. In addition, the parasite density in pregnant women with infection on days 7 and 14 was significantly lower for those receiving pyrimethamine with sulfadoxine and chlorproguanil with dapsone than for those receiving chloroquine. Chloroquine use in the preceding two weeks was not related to the response to any treatment. Pyrimethamine with sulfadoxine kept patients free of parasites longer than the other drugs did, most likely because of its longer half life. Of the primigravid women, $81 \%$ remained aparasitaemic through to day 28 after receiving pyrimethamine with sulfadoxine compared with $33 \%$ who received chlorproguanil with dapsone and $24 \%$ who received chloroquine. We do not know if the placentas were infected; no good correlation has been found between the parasite density in peripheral blood and in the placenta of women with well developed immunity. ${ }^{34}$

We found a rise in haemoglobin concentration from day 0 to day 28 for all pregnant women except primigravid recipients of chloroquine. A relation between absence of peripheral parasites from day 0 to day 28 and an increase in haemoglobin was not found but might have been found if we had not treated the women who were positive for parasites and who had symptoms of malaria before day 28 . At day 42 we saw a relation between aparasitaemia and the continuous rise in haemoglobin concentration. Malaria is an important cause of anaemia in pregnant women; anaemia increases in the second trimester, following (but not coinciding with) the highest prevalence of malaria infection. The peak density of parasitaemia in primigravidas is at 9 to 16 weeks' gestation; it has been asserted that to improve haemoglobin concentrations after this time requires the use of both antimalarial drugs and folic acid. ${ }^{3}$ In 1969 Gilles et al found no difference in the outcome of pregnancy or anaemia in primigravid women treated throughout pregnancy with antimalaria drugs either alone or in combination with folic acid. ${ }^{1}$ We did not supply patients with folic 
acid because it might have inhibited the action of sulfadoxine against $P$ falciparum ${ }^{18}$ and would have introduced an uncontrolled variable. None the less, we did observe a significant increase in haemoglobin concentrations in most women even during the short interval of our study.

We did not see any signs of pyrimethamine and sulfadoxine toxicity, such as jaundice or dermatitis, in our patients. Fatal skin reactions to pyrimethaminesulfadoxine combination have been reported in one in 20000 American travellers who used pyrimethamine $25 \mathrm{mg}$ and sulfadoxine $500 \mathrm{mg}$ once a week for prophylaxis and in one in 5000 persons who received multiple doses for a total of $2.6 \mathrm{~g}$ of sulfadoxine.$^{89}$ Predisposition to these adverse effects has not been reported in pregnancy.

We also did not notice side effects of dapsone. Dapsone toxicity is usually related to dose and duration of treatment. Haemolysis and methaemoglobinaemia occur after two to three weeks of continuous treatment but rarely lead to anaemia and cyanosis if doses are kept below $300 \mathrm{mg}$ daily. Glucose 6-phosphate dehydrogenase deficiency increases the risk of haemolysis induced by dapsone. ${ }^{19}{ }^{20}$ With the low single dose we used $(150 \mathrm{mg}$ ) we did not see overt haemolysis; however, the distribution of glucose 6-phosphate dehydrogenase deficiency in Kenya is uneven, and we did not rule out the presence of this anomaly in our patients. Agranulocytosis is also a dose dependent and rare phenomenon (only 23 cases rèported $)^{21}$ and is seen predominantly when dapsone is combined with other drugs. ${ }^{22} 23$ Hypersensitivity reactions were thought to occur after several weeks of more than $100 \mathrm{mg}$ dapsone daily, ${ }^{192}$ but recently the so called dapsone syndrome was noticed after only four weeks of Maloprim (dapsone $100 \mathrm{mg}$ and pyrimethamine $12.5 \mathrm{mg}$ ) and chloroquine $300 \mathrm{mg}$ taken weekly for prophylaxis. ${ }^{25}$

Except for chlorproguanil all the drugs we used have been studied in pregnancy. No embryotoxic or teratogenic effects were noted in pregnant rats fed high doses of proguanil or cycloguanil, ${ }^{26}$ but inhibition of development of ova during cleavage was found. ${ }^{27}$ Proguanil and chlorproguanil have been widely recommended for prophylaxis in pregnancy and have been used without apparent adverse effects. Pyrimethamine has been reported to be teratogenic when given in high doses to rats, although teratogenicity has never been observed in humans. Maloprim has no embryopathic effect when given in a single dose each week. ${ }^{28-30}$

Sulpha drugs compete with bilirubin and could cause raised concentrations of unbound bilirubin, and possibly kernicterus, in neonates. However, this is seldom seen after sulphonamide use. ${ }^{31}$ A teratogenic effect of sulfadoxine has been looked for in animals ${ }^{32}$ and pregnant women ${ }^{29}{ }^{33}$ but has not been observed. SDDS (2-sulphamoyl-4,4-diamino-diphenylsulphone) was not teratogenic when given to rats. ${ }^{27} \mathrm{~A}$ low incidence $(3.4 \%)$ of defects was seen in children born to women with leprosy who took sulphones during pregnancy. ${ }^{34}$

The World Health Organisation advocates pyrimethamine with sulfadoxine for the treatment in pregnancy of falciparum malaria resistant to chloroquine. ${ }^{5}$ Resistance to pyrimethamine and sulfadoxine is still uncommon in Kenya, ${ }^{35}$ but extensive use of this drug combination has led to the emergence of parasites resistant to the drug in South East Asia. ${ }^{36}$ Because the development of a higher level of resistance to pyrimethamine and sulfadoxine remains a risk in Africa we believe that it is desirable to study other drug combinations.

The combination of chlorproguanil and dapsone has not been investigated in pregnant animals or women, as far as we know. In Vietnam dapsone $25 \mathrm{mg}$ was added to proguanil $200 \mathrm{mg}$ by the Australian military because prophylaxis with proguanil failed. The frequency of malaria attacks dropped dramatically after this measure. ${ }^{23}$ The low doses of chlorproguanil and dapsone, which have no documented teratogenicity when given on their own, and the lack of side effects observed by us and others ${ }^{13}$ lead us to believe that chlorproguanil and dapsone is probably a safe drug combination. Experimental testing would, however, be required to confirm that the combination is safe before its use could be widely recommended. The advantages of chlorproguanil and dapsone over pyrimethamine and sulfadoxine are those of stronger activity against Kenyan $P$ falciparum in vitro ${ }^{13}$ and lower cost. It is possible that no drug will maintain the placenta entirely free of parasites, but this may not be necessary to prevent anaemia in the mother and low birth weight of the baby.

Giving a drug during monthly antenatal clinic visits would assure better compliance, and the drug might have a beneficial effect on maternal anaemia and pregnancy outcome if it reliably cured peripheral parasitaemia. Chlorproguanil and dapsone as a drug combination for such intervention in pregnancy warrants further study.

We thank Professor M Mugambi and Dr D K Koech, former and present directors, Kenya Medical Research Institute, for permission to publish our findings, and $\mathrm{Dr}$ Teunis Eggelte for performing the ELISA inhibition tests for chloroquine and ELISA tests for dapsone, pyrimethamine, sulfadoxine, and chlorproguanil.

1 Gilles HM, Lawson JB, Sibelas M, Voller A, Allan N. Malaria, anaemia and pregnancy. Ann Trop Med Parasitol 1969;63:245-63.

2 Bray RS, Anderson MJ. Falciparum malaria and pregnancy. Trans $R$ Soc Trop Med Hyg 1979;73:427-31.

3 Brabin BJ. An analysis of malaria in pregnancy in Africa. Bull WHO 1983;61:1005-16

4 McGregor IA. Epidemiology, malaria and pregnancy. Am $\mathcal{F}$ Trop Med Hyg 1984;33:517-25.

5 World Health Organisation. Advances in malaria chemotherapy. WHO Tech Rep Ser 1984;711.

6 Steketee RW, Brandling-Bennett AD, Kaseje DC, Schwartz IK, Churchill FC. In vivo response of Plasmodium falciparum to chloroquine in pregnan and non-pregnant women in Siaya district, Kenya. Bull WHO 1987;65: $885-90$

7 Hatton CS, Peto TE, Bunch C, et al. Frequency of severe neutropeni associated with amodiaquine prophylaxis against malaria. Lancet 1986; 411-3.

8 Hernborg A. Stevens-Johnson syndrome after mass prophylaxis with sulfadoxine for cholera in Mozambique. Lancet 1985;ii:1072-3.

9 Peters W. Chemotherapy and drug resistance in malaria. London: Academic Press, 1987:648-58.

10 Nguven-Dinh P, Spencer HC, Chemangey-Masaba S, Churchill FC. Susceptibility of Plasmodium falciparum to pyrimethamine and sulfadoxine pyrimethamine in Kisumu, Kenya. Lancet 1982;i:823-5.

11 Spencer HC, Watkins WM, Sixsmith DG, Koech DK. Response of Plasmodium falciparum to dihydrofolate reductase inhibitors in Malindi, Kenya. Trans $R$ Soc Trop Med Hyg 1986;80:201-3.

12 Watkins WM, Brandling-Bennett AD, Oloo AJ, Howells RE, Gilles HM Koech DK. Inadequacy of chlorproguanil $20 \mathrm{mg}$ per week as chemoprophy laxis for falciparum malaria in Kenya. Lancet 1987;i:125-7.

13 Watkins WM, Brandling-Bennett AD, Nevill CG, Carter JY, Boriga DA Howells RE. Chlorproguanil/dapsone for the treatment of non-severe falciparum malaria in Kenya: a pilot study. Trans $R$ Soc Trop Med $H y$ 1988;8:398-403

14 Shenton FC, Bots M, Menon A, Eggelte TA, de Wit M, Greenwood BM. An ELISA test for detecting chloroquine in urine. Trans $R$ Soc Trop Med Hyg $1988 \cdot 82 \cdot 216-20$.

15 Almeoda-Filho H, Souz JM. A simple urine test for sulfonamides. Bull WHO 1983;61:1167-8.

16 Greenwood BM, Greenwood AM, Bradley AK, et al. ELISA tests for dapsone and pyrimethamine and their application in a malaria chemoprophylaxis programme. Bull WHO 1986;64:903-16.

17 Brabin BJ. Malaria in pregnancy [Abstract]. In: Kager PA, Polderman AM, eds. Proceedings of the XIIth international congress for tropical medicine and malaria. Amsterdam: Excerpta Medica, 1988:5. (Excerpta Medica International Congress, series 810 .

18 Milhous WK, Weatherly NF, Bowdre JH, Desjardins RE. In vitro activities of and mechanisms of resistance to antifol antimalarial drugs. Antimicrob Agents Chemother 1985;27:525-30.

19 Graham WR. Adverse effects of dapsone. Int I Dermatol 1975;14:494-500.

20 DeGowin RL. A review of therapeutic and haemolytic effects of dapsone. Arch Intern Med 1967;120:242-8.

21 Weetman RM, Boxer LA, Brown MP, Mantich NM, Baehner RL. In vitro inhibition of granulopoiesis by 4-amino-4' -hydroxylaminodiphenyl sulfone. Br 7 Haematol 1980;45:361-70.

22 Smithurst BA, Robertson I, Naughton MA. Dapsone-induced agranulocytosis complicated by gram-negative septicaemia. Med f A Aust 1971;1:537-9.

23 Black RH. Malaria in the Australian army in South Vietnam. Successful use of a proguanil-dapsone combination for chemoprophylaxis of chloroquine resistant falciparum malaria. Med J A ust 1973;1:1265-70. 
24 Smith WC. Are hypersensitivity reactions to dapsone becoming more frequent? Lepr Rev 1988;59:53-8

25 Grayson ML, Yung AP, Doherty RR. Severe dapsone syndrome due to weekly Maloprim. Lancet 1988; ; 531 .

26 Ferone R. Antimalarial drugs. II. In: Handbook of experimental pharmacology 68/II. Peters W, Richards WH, eds. Berlin: Springer-Verlag, 1985.

27 Cutting W. Antifertility effects of biguanides. Antibiot Chemother 1962;12: 671-5.

28 Anonymous. Pyrimethamine combinations in pregnancy. Lancet 1983;ii: $1005-7$

29 Von Hengst P. Untersuchungen zur Teratogenität des Daraprim (pyrimethamin) beim Menschen. Zentrabl Gynakol 1972;94:551-5.

30 Bruce-Chwatt LJ. Màlaria and pregnancy. Br Med F 1983;286:1457-8.

31 Scholer HJ. Assessment of the safety of Fansidar to pregnancy. Animal and human data. Geneva: World Health Organisation, 1983. (MAP/SGPM/ INF83.6.)

32 Bohni E, Fust B, Rieder J, Schaerer K, Havas I. Comparative toxicological, chemotherapeutic and pharmacokinetic studies with sulphormethoxine and other sulphonamides in animals and men. Chemotherapy 1969;14:195-226.

33 Barbosa JC, Ferreira I. Sulfadoxine-pyrimethamine (Fansidar) in pregnan women with toxoplasma antibody titers. In: Siegenthaler $\mathbf{W}$, Luethy $\mathbf{R}$ eds. Current Chemotherapy. Proceedings of the Xth international congress of chemotherapy. Zurich: American Society of Microbiology 1978:134-5.

34 Maurus JN. Hansen's disease in pregnancy. Obstet Gynecol 1978;52:22-5.

35 Spencer HC, Watkins WM, Sixsmith DG, Koech DK, Chulay JD. A new in vitro test for pyrimethamine/sulfadoxine susceptibility of Plasmodium falciparum and its correlation with in vivo resistance in Kenya. Bull WHO 1984;62:615-21.

36 Pinchepongse S, Doberstyn EB, Cullen JR, Yisunri L, Thongsombun Y, Thimasaran K. An evaluation of five regimens for the out-patient therapy of falciparum malaria in Thailand. Bull WHO 1982;60:907-12.

(Accepted 25 April 1990)

\title{
Referral letters and replies from orthopaedic departments: opportunities missed
}

\author{
L G H Jacobs, M A Pringle
}

\begin{abstract}
Objective-To study delays between sending referral letters and the outpatient appointment and to assess the content of referral and reply letters, their educational value, and the extent to which questions asked are answered by reply letters.

Design-Retrospective review of referrals to 16 consultant orthopaedic surgeons at five hospitals, comprising 288 referral letters with corresponding
\end{abstract} replies, by scoring contents of letters.

Setting-Orthopaedic teaching hospitals in Nottingham, Derby, and Mansfield.

Main outcome measures-Weighted scores of contents of referral and reply letters, assessment of their educational value, and responses to questions in referral letters.

Results-Median outpatient delay was 23.4 weeks. There was no significant decrease in waiting time if the referral letter was marked "urgent" but a significantly greater delay $(p<0.01)$ if referrals were directed to an unnamed consultant. The content score was generally unsatisfactory for both referrals and replies, and there was no correlation for the content scores of the referral letter and its reply $(r=0 \cdot 13)$. Items of education were rare in the referral letters $(8 / 288 ; 3 \%)$ and significantly more common in replies $(75 / 288 ; 26 \%)(p<<0.001)$. Senior registrars were significantly more likely to attempt education than other writers $(p<0 \cdot 02)$. Education in replies was significantly related to increased length of the letter $(p<0.05)$ and was more likely to occur if the referral was addressed to a named consultant $(p<0.03) .48$ (17\%) Referral letters asked questions, of which 21 (44\%) received a reply. No factor was found to influence the asking of or replying to questions.

Conclusions - The potential for useful communication in the referral letter and in the reply from orthopaedic surgeons is being missed at a number of levels. The content is often poor, the level of mutual education is low, and the use of the referral letter to determine urgency is deficient. Most questions asked by general practitioners are not answered.

\section{Introduction}

Although there is evidence of improvement in the content of referral letters, ${ }^{12}$ Hull and Westerman reported in 1986 that $27 \%$ of referral letters to a medical department were barely adequate or else absent or poor. ${ }^{3}$ Partly as a response, standardisation of the contents of referral letters for each specialty has been suggested. ${ }^{146}$ Further problems with the referral process lie in the considerable delays between referral and the outpatient visit and in the omission of important details from the hospital replies, which rarely answer questions posed by general practitioners in their referral letters. ${ }^{7-9}$

Traditionally, doctors obtain continuing medical education from postgraduate meetings and medical journals. Other potential sources are professional correspondence, the lay press, pharmaceutical representatives, informal meetings with professional colleagues, and patients. Letters are important in "the educative role of consultants" and as a medium for "the process of mutual education." It could therefore be asked whether and to what extent general practitioners receive education in replies from orthopaedic surgeons in response to their referral letters; whether those general practitioners in most need of such education (as indicated by poor content of the referral letter) receive it most often; and whether general practitioners impart any education regarding the patients they refer.

Studies have analysed the contents (but not the educational potential) of letters for general medical and psychiatric referrals, ${ }^{156}$ but no studies have examined orthopaedic referrals and their replies. Thus the aims of this study were to assess: the delay between writing the referral letter and the outpatient appointment; the content of the referral letters from general practitioners to orthopaedic surgeons and their associated replies; the extent to which mutual education occurs between general practitioners and orthopaedic surgeons and the factors that influence such education; and the extent to which questions asked by referral letters are answered in the reply.

\section{Method}

Referrals to elective outpatient clinics of 16 consultant orthopaedic surgeons at Nottingham General Hospital, City Hospital (Nottingham), Mansfield District General Hospital, Harlow Wood Orthopaedic Hospital (near Mansfield), and the hand surgery unit at Derby Royal Infirmary were reviewed retrospectively. The letters from the first 20 new patients attending each consultant's clinic after 1 October 1988 were used. The referral letter(s) and all replies from orthopaedic surgeons to the general practitioner in the month after the patient was seen were photocopied. Any details identifying authors were coded and then removed before assessment. 